\title{
Reuse of red powder of steel plants as fine addition in ceramic bricks manufacture
}

\author{
N. Quaranta ${ }^{1}$, M. Caligaris ${ }^{1}$, H. López ${ }^{1}$, M. Unsen ${ }^{1}$, G. Pelozo ${ }^{1}$, \\ J. Pasquini ${ }^{1} \&$ A. Cristóbal ${ }^{2}$ \\ ${ }^{1}$ Universidad Tecnológica Nacional, F. R. San Nicolás, Argentina \\ ${ }^{2}$ INTEMA, CONICET, UNMdP, Mar del Plata, Argentina
}

\begin{abstract}
The recycling of industrial wastes as raw material for the construction industry emerges as a viable solution to the increasingly serious problem of their accumulation, due to increasing production. This recycling process involves significant environmental benefits: the use of wastes, energy economy and the conservation of nonrenewable resources.

In this paper waste from a steel plant, called red powder or Ruthner powder, is studied, in order to determine its environmental suitability for reuse as fine aggregate in mixtures for the production of clay bricks. This waste is produced in the steel industry after the hot rolling process; the plate is covered with a layer of oxides which is removed in a pickling process, obtaining as a byproduct of the process $\mathrm{Fe}_{2} \mathrm{O}_{3}$ (red powder).

These powders are mixed with clay up to $50 \%$, pressed and heat treated in the range $950^{\circ} \mathrm{C}-1000^{\circ} \mathrm{C}$.

Ceramic compacts thus obtained are characterized by several techniques for determining the suitability for using them, taking into account the commercial requirements of such materials. These products have good physical and mechanical properties, with values of porosity, mechanical strength, volumetric changes and permanent weight loss within the market requirements.
\end{abstract}

Keywords: metallurgical wastes, recycle, red powder, ceramics. 


\section{Introduction}

In the manufacture of flat steel products, after the hot rolling process, the plate is covered with a layer of oxides. This layer is removed before the cold rolling process through a process of pickling with hydrochloric acid $(\mathrm{HCl})$. Due to the formation of iron chloride $\left(\mathrm{FeCl}_{2}\right), \mathrm{HCl}$ loses its ability to remove iron oxide (II) $(\mathrm{FeO})$ from the surface. Therefore, continuously new acid is mixed in the container and the used acid is collected at one end thereof [1].

In the exhausted pickling solutions, a metal content of up to $150-250 \mathrm{~g} / \mathrm{L}$ is observed. The ranges of concentration of acid and iron ions are very broad, making it difficult to select a universal method for the regeneration of these solutions. The recovery of the acid is an important issue both from the environmental and the economical points of view, so the methods that allow efficient reuse of the pickling acids are being investigated and developed [2]. In the case of the steel industry, the pyrohydrolysis is the preferred technology for the regeneration of hydrochloric acid from depleted pickling solutions, obtaining $\mathrm{Fe}_{2} \mathrm{O}_{3}$ as a byproduct [3]. This technology can be performed using fluidized bed processes and processes of spray-roasting. In the fluidized bed process the produced iron oxide powder is porous, of low density, and is considered a valuable raw material for ceramic and chemical industries [4]. The sprayroasting process allows almost complete recovery of hydrochloric acid in a closed cycle. The iron oxide that is additionally obtained, called also Ruthner powder, is a brown or red hematite, which is considered an important raw material in various industry sectors, such as the production of ferrite, colors and pigments [5-8].

In this paper the feasibility of reusing this waste, to be called red powder or Ruthner powder (PR), as fine aggregate in mixtures for the production of clay bricks, is studied.

\section{Experimental}

The raw materials, Ruthner powder and clay, are granular materials and have been characterized by different techniques: optical (OM) and scanning electron microscopy (SEM), energy dispersive analysis X-ray (EDS), $\mathrm{pH}$ and conductivity, X-ray diffraction (XRD), particle size and morphology analysis, differential thermal analysis and thermogravimetric analysis (DTA-TGA), weight loss on ignition (LOI), among others.

The X-ray diffraction diagrams of these powders were obtained with a PANalytical X'Pert PRO equipment with $\mathrm{CuK} \alpha$ radiation $(\lambda=1.5406 \mathrm{~nm})$. Operating conditions were $40 \mathrm{kV}, 40 \mathrm{~mA}$. SEM analysis was performed with a scanning electron microscope Philips 515, with energy dispersive analyzer (EDAX-Phoenix). The DTA-TGA tests were performed on a Shimadzu equipment DTA-50, TGA-50 with analyzer TA-50 WSI.

The conductivity and $\mathrm{pH}$ of the waste were measured with SPER SCIENTIFIC, Model 860032, and Altronix TPX-III, equipment respectively, 
after two hours of stirring at room temperature at a rate of $10 \mathrm{~g}$ of waste powder in $100 \mathrm{ml}$ of demineralized water.

In the case of powder raw materials, weight loss on ignition was determined after heat treatment at $800^{\circ} \mathrm{C}$ for 3 hours.

Leaching tests were performed according to EPA Standard 1310, with analysis of heavy metals in the leachate. Chemical analysis of leachate was performed by plasma emission spectrometry with an ICP Perkin Elmer Optima $3100 \mathrm{XL}$.

Ruthner powder was added to the base clay to obtain mixtures of the following proportions $0 \%, 5 \%, 10 \%, 20 \%, 30 \%, 40 \%$ and $50 \%$. A moisture content of $8 \%$ was added to these mixtures. The samples were obtained by uniaxial pressure of $25 \mathrm{MPa}$ in a rectangular mold of $40 \mathrm{~mm} \times 70 \mathrm{~mm}$, resulting thickness of approximately $16 \mathrm{~mm}$.

The compact bodies obtained were heat treated at temperatures of $950^{\circ} \mathrm{C}$ and $1000^{\circ} \mathrm{C}$ for 3 hours.

Sintered products were characterized by standard techniques that lead to determine the physicochemical, morphological and mechanical properties that allow establishing the service aptitude. Such techniques include: porosity, weight loss, permanent volumetric variation, resistance to compression, among others.

From now onwards, the samples are named as follows:

PR0: clay sample without added wastes, taken as a reference.

PR5: sample with 5\% of added waste.

PR10: sample with $10 \%$ of added waste.

PR20: sample with $20 \%$ of added waste.

PR30: sample with $30 \%$ of added waste.

PR40: sample with $40 \%$ of added waste.

PR50: sample with $50 \%$ of added waste.

\section{Results and discussion}

\subsection{Raw materials characterization}

Chemical analysis of the waste and the clay is presented in Table 1, expressed as a percentage of the elements, regardless the carbon content in the samples. In the waste sample $\mathrm{C}$ it is not detected, and in the clay sample $24 \% \mathrm{C}$ it is detected, which could be organic or inorganic matter of carbonate type. A high content of Fe can be observed in the studied waste.

Table 1: $\quad$ Semi quantitative chemical analysis of the materials.

\begin{tabular}{|c|c|c|c|c|c|c|c|c|}
\cline { 2 - 9 } \multicolumn{1}{c|}{} & $\mathrm{Mg}$ & $\mathrm{Al}$ & $\mathrm{Si}$ & $\mathrm{Cl}$ & $\mathrm{K}$ & $\mathrm{Ca}$ & $\mathrm{Mn}$ & $\mathrm{Fe}$ \\
\hline PR & -- & 0.78 & 1.22 & 0.49 & -- & -- & 0.96 & 96.55 \\
clay & 4.53 & 26.49 & 58.39 & --- & 5.83 & 1.46 & --- & 3.30 \\
\hline
\end{tabular}

Weight loss on ignition of these materials was $0.02 \%$ for PR and $1.12 \%$ for the clay. 
The microscopic appearance of the waste is shown in Figure 1, where the morphology and particle size can be observed. The red powder is a very finegrained material. This is important during the process of transporting the material either for reuse or disposal in landfills, due to the possibility of dispersion of particulate matter producing air pollution.

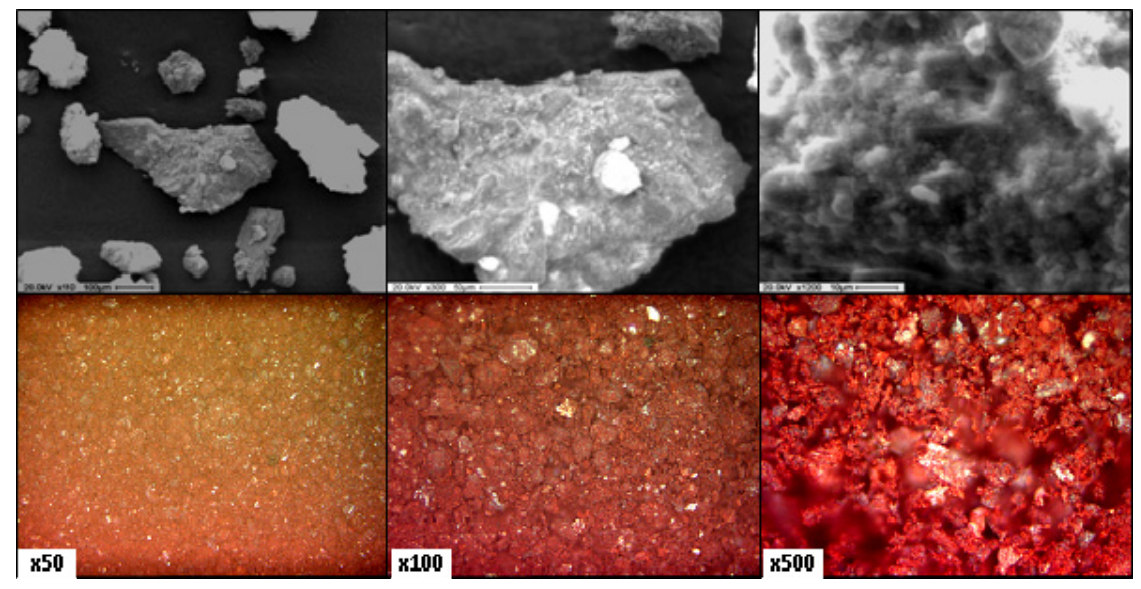

Figure 1: $\quad$ SEM (superior) and OM (inferior) images of the Ruthner powder.

Figure 2 shows the XRD pattern of the Ruthner powder. This sample only presents the phases iron and hematite (identified by pdf 870721 and pdf 84-0306 respectively).

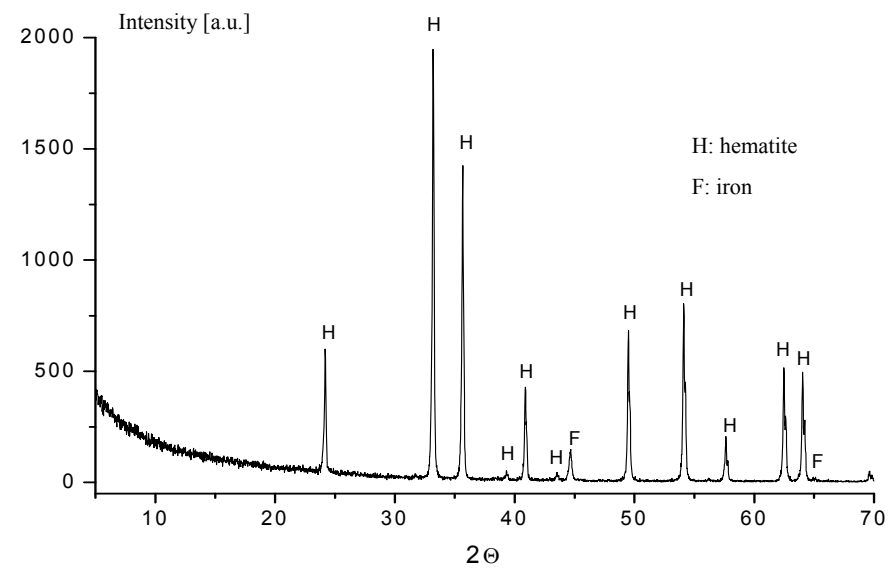

Figure 2: $\quad$ XRD of Ruthner powder. 
The particle sizes of the powders, determined by SEM, are between $1.5 \mathrm{~mm}$ and $1 \mu \mathrm{m}$. Figure 3 presents the particle size distribution, showing that more than $92 \%$ of the particles sizes are less than $250 \mu \mathrm{m}$.

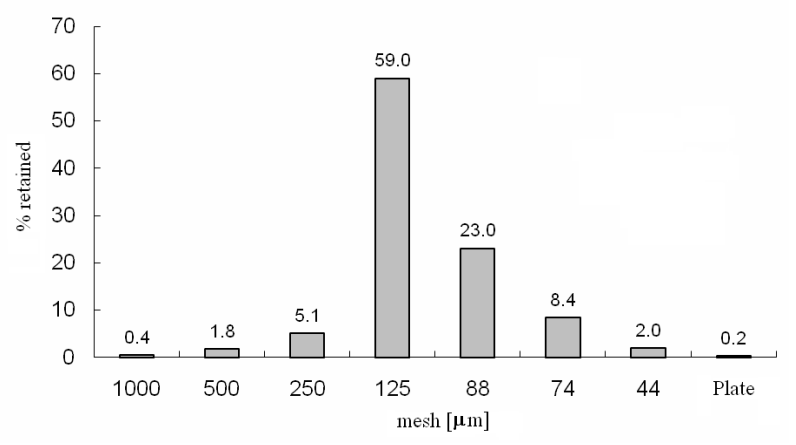

Figure 3: Particle size distribution of Ruthner powder.
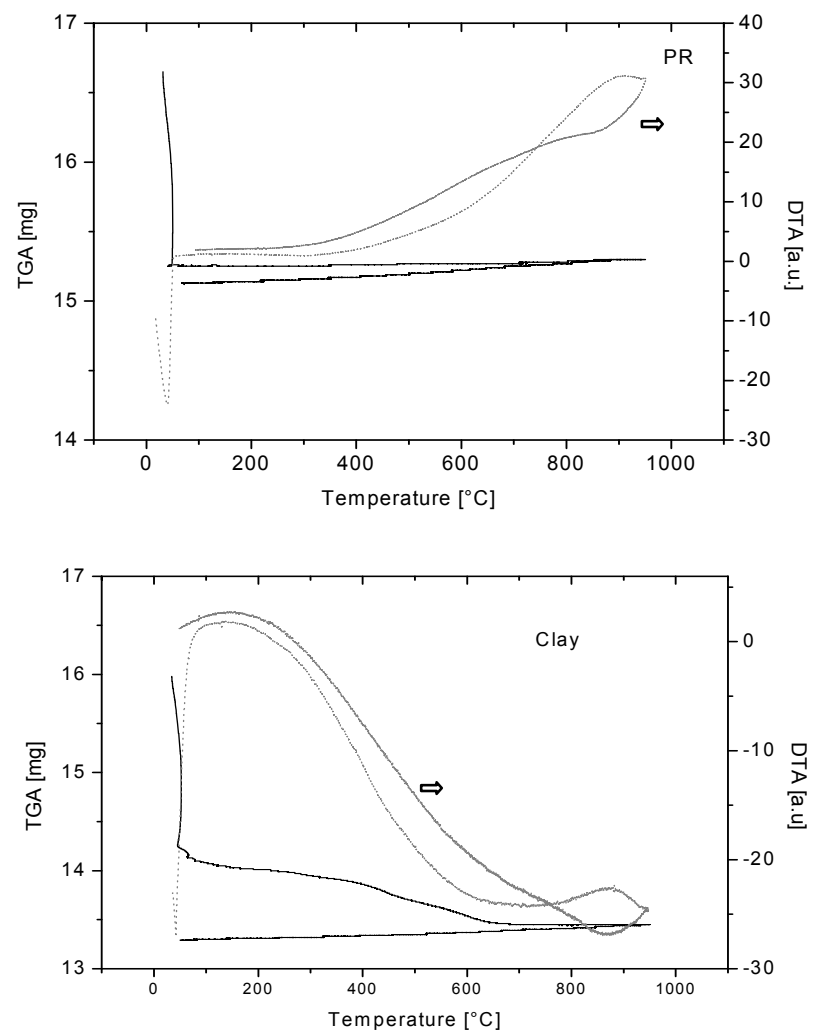

Figure 4: DTA-TGA curves of the studied materials. 
DTA-TGA analysis of raw materials, clay and Ruthner powder, is shown in Figure 4. The residual material shows neither weight loss nor peaks in the DTA curve. This result is expected, taking into account the XRD observations that indicate the presence of $\mathrm{Fe}_{2} \mathrm{O}_{3}$, and the low values obtained from weight loss on ignition.

The clay sample shows a typical curve for this type of material, with weight loss between $200^{\circ} \mathrm{C}$ and $700^{\circ} \mathrm{C}$. This can be assigned to different reactions, up to $400^{\circ} \mathrm{C}$ an endothermic reaction of dehydroxylation of the clay and up to $700^{\circ} \mathrm{C}$ combustion of organic material and the decomposition reaction of calcite. In the range $850^{\circ} \mathrm{C}-950^{\circ} \mathrm{C}$ a peak in the DTA curve is registered, without weight loss. This peak can be assigned to the phase transformation of aluminosilicates present in the sample, which is a reversible reaction.

Another important parameter to measure, especially when the waste will be used as filler to improve roads or elevate soil, are $\mathrm{pH}$ and conductivity, because these values allow to infer the possible influence of these residues in the soil layers when they are deposited.

These parameters were determined in the residues studied, at room temperature and after 2 hours with stirring. For Ruthner powder, the values obtained were 7.49 for $\mathrm{pH}$ and $0.66 \mathrm{mS}$ for conductivity, values considered appropriate given the standard values for these parameters in different soils [9].

Table 2 presents the analysis of leaching liquid of the waste. These tests reflect the possibility to transfer some elements into soil base in case of deposition of these wastes in landfills, constituting a means of transfer to surface water or groundwater.

Table 2: $\quad$ Analysis of leachate of the waste.

\begin{tabular}{|c|cccccccc|}
\hline Element & $\mathrm{Pb}$ & $\mathrm{Cd}$ & $\mathrm{Ni}$ & $\mathrm{Mn}$ & $\mathrm{Cr}$ & $\mathrm{Co}$ & $\mathrm{Zn}$ & $\mathrm{Cu}$ \\
\hline $\begin{array}{c}\mathrm{PR} \\
{[\mathrm{mg} / \mathrm{l}]}\end{array}$ & $<0.01$ & $<0.01$ & 0.11 & 1.61 & $<0.01$ & $<0.01$ & 0.20 & 0.32 \\
\hline
\end{tabular}

The results of the leaching test of these powders are analyzed taking into account the definitions and limits set out in Regulatory Decree of the Law 24 051 (Argentina) on hazardous waste regime (Decree 831/93) to determine the risk of this process of leaching. The decree, in Annex IV, identifies a waste as hazardous, based on their risk characteristics: ignitability, corrosivity, reactivity, leachability and toxicity, radioactivity, among others.

In relation to the property being analyzed, called the leachability in the mentioned document, a list of 25 elements and compounds is presented. The concentration limits are detailed in Annex VI of the same decree.

In the case of the studied waste, the following elements were determined in leachate: $\mathrm{Pb}, \mathrm{Cd}, \mathrm{Ni}, \mathrm{Mn}, \mathrm{Cr}, \mathrm{Co}, \mathrm{Zn}$ and $\mathrm{Cu}$. The results indicate that this residue can be used for the mentioned use; this is as fine aggregate of bricks and may even be disposed in landfill without risk. 


\subsection{Raw materials characterization}

The mixture of raw materials, clay and PR, can be easily done without agglomerates of the components, and even with low percentages of residue the obtained samples have an intense color.

After heat treatment, the samples present more intense colors with increasing waste powder content, which implies a benefit from the commercial point of view. Figure 5 shows the compact bodies obtained.

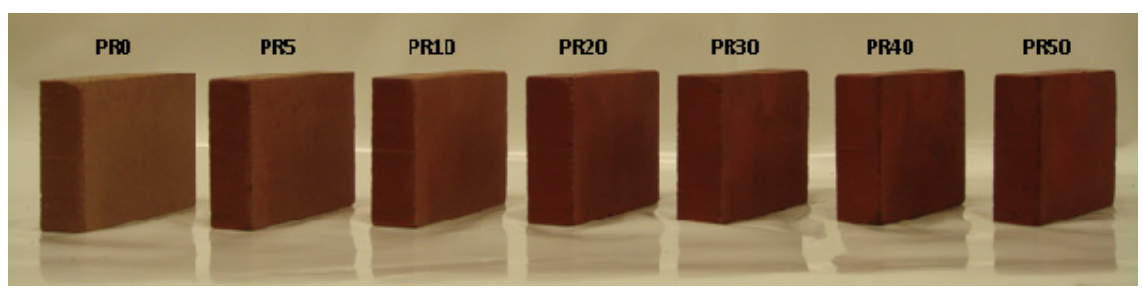

Figure 5: $\quad$ Sintered bodies of clay and Ruthner powder.

It can be seen that these products are very homogeneous in colors. They have well-defined edges and corners without shelling of the structure.

Samples PR0, PR5, PR10 and PR20 sintered at $950^{\circ} \mathrm{C}$, while those with higher PR content sintered at $1000^{\circ} \mathrm{C}$.

Figure 6 shows the values determined for permanent volumetric variation (PVV) and weight loss on ignition (LOI) of these materials. The samples with lower PR content have similar parameters to those of the clay, while for samples with more than $20 \%$ waste, variations in direct relation to the contents of the waste were determined. The lower weight loss is observed for the sample with higher levels of PR, which is logical in terms of the LOI determined for raw materials. For PVV values, a maximum decrease of about $12 \%$ for PR50 is observed. Despite being a high value of volumetric variation, these samples show no cracking or macroscopic visible cracks.
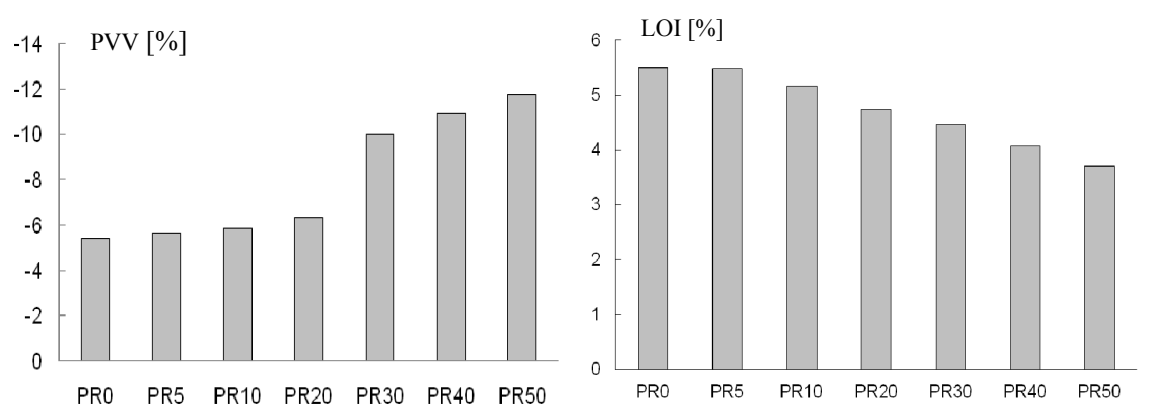

Figure 6: Permanent volumetric variation and weight loss on ignition. 


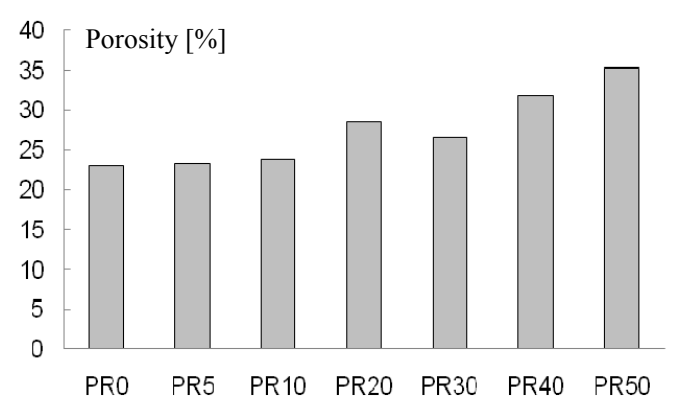

Figure 7: $\quad$ Porosity of the sintered bodies.

Figure 7 shows the porosity values of these sintered samples. It is observed that with increasing PR content in the samples, the porosity of the bricks increases. It can be seen a discontinuous behavior of these values in the sample PR20, which can be assigned to the change in temperature of treatment. The same behavior can be seen in the results of tests of flexural strength, shown in Figure 8 along with the values of compressive strength for these samples.
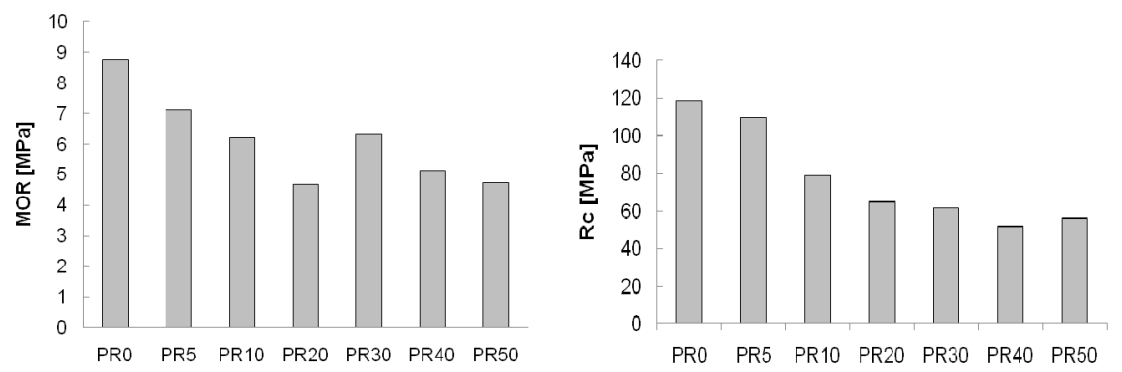

Figure 8: $\quad$ Flexural and compressive strength for these samples.

The compressive strengths obtained are within the standards required for commercial parts even for samples with higher content of waste.

The required compressive strength for building blocks, clay based, is more than 10.3 $\mathrm{MPa}, 17.2 \mathrm{MPa}$ and $20.7 \mathrm{MPa}$ for environmental requirements (temperature and humidity) low, moderate and severe respectively, according to ASTM C62-04. Compressive strength higher than 10.0 MPa is set by Spanish standards for this type of ceramic (NSE FL90-Royal Decree 1723/1990).

All the obtained results lead to the conclusion that there is a high feasibility of reuse of this type of waste as raw material for building bricks.

\section{Conclusions}

In this paper, red powder from steel processing industries is studied in order to determine its feasibility for reuse as raw material in the production of 
construction ceramics. In a first stage, the raw material characterization suggests environmental suitability of this waste, with values of leaching, $\mathrm{pH}$, conductivity, not exceeding the limits set for disposal in landfills. The physicochemical analysis of raw materials leads to the design of clay-residue mixtures containing up to $50 \%$ waste. The firing temperatures were $950^{\circ} \mathrm{C}-$ $1000^{\circ} \mathrm{C}$.

The sintered products have good physical and mechanical properties, with values of porosity, mechanical strength, permanent volumetric changes and weight loss on ignition within the requirements of the market for these products.

\section{Acknowledgements}

The authors wish to thank the Commission of Scientific Research of Buenos Aires Province, Argentina, and the National Agency of Technological and Scientific Promotion, Argentina, for the financial supports received for this work.

\section{References}

[1] Kladnig W.F., New Development of Acid Regeneration in Steel Pickling Plants, Journal of Iron and Steel Research International, Vol. 15 [4], pp. 0106 (2008).

[2] Regel-Rosocka M., A review on methods of regeneration of spent pickling solutions from steel processing, Journal of Hazardous Materials, Vol. 177, pp. 57-69 (2010).

[3] Souza Ferreira A., Borges Mansur M., Statistical analysis of the spray roasting operation for the production of high quality $\mathrm{Fe}_{2} \mathrm{O}_{3}$ from steel pickling liquors, Process Safety and Environment Protection, Vol. 89 [3], pp. 172-178 (2011).

[4] Kladnig W.F., A review of steel pickling and acid regeneration: an environmental contribution, International Journal of Materials \& Product Technology, Vol. 19 [6], pp. 550-561 (2003).

[5] http://www.acreg.com (ACREG Process Technology GmbH).

[6] Mozaffari M., Amighian J., Preparation of Al-substituted Ni ferrite powders via mechanochemical processing, Journal of Magnetism and Magnetic Materials, Vol. 260, pp. 244-249 (2003).

[7] Zaspalis V., Kolenbrander M., Design principles for spray-roasted iron oxides for the manufacturing of ferrites, Powder Technology, Vol. 161, pp. 169-174 (2006).

[8] Zaspalis V., Kolenbrander M., Mixing homogeneity and its influence on the manufacturing process and properties of soft magnetic ceramics, Journal of Materials Processing Technology, Vol. 205, pp. 297-302 (2008).

[9] Pansu M. and Gautheyrou J., Handbook of Soil Analysis. Mineralogical, Organic and Inorganic Methods., Ed. Springer, Berlin, Heidelberg, New York, 2006. 